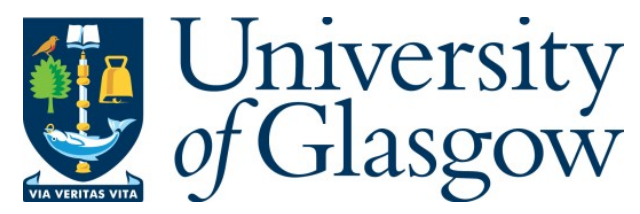

Najda, S. P. et al. (2016) AlGaInN laser diode technology for GHz high-speed visible light communication through plastic optical fiber and water. Optical Engineering, 55(2), 026112. (doi:10.1117/1.OE.55.2.026112).

Copyright 2016 Society of Photo-Optical Instrumentation Engineers. One print or electronic copy may be made for personal use only. Systematic reproduction and distribution, duplication of any material in this paper for a fee or for commercial purposes, or modification of the content of the paper are prohibited.

http://eprints.gla.ac.uk/129845/

Deposited on: 10 October 2016

Enlighten - Research publications by members of the University of Glasgow http://eprints.gla.ac.uk 


\section{Optical Engineering}

\section{AlGaInN laser diode technology for GHz high-speed visible light communication through plastic optical fiber and water}

Stephen P. Najda

Piotr Perlin

Tadek Suski

Lucja Marona

Mike Leszczyński

Przemek Wisniewski

Robert Czernecki

Robert Kucharski

Grzegorz Targowski

Malcolm A. Watson

Henry White

Scott Watson

Antony E. Kelly 


\title{
AlGalnN laser diode technology for GHz high-speed visible light communication through plastic optical fiber and water
}

\author{
Stephen P. Najda, ${ }^{a, \star}$ Piotr Perlin, ${ }^{a, b}$ Tadek Suski, ${ }^{b}$ Lucja Marona, ${ }^{b}$ Mike Leszczyński, ${ }^{a, b}$ Przemek Wisniewski, ${ }^{a, b}$ \\ Robert Czernecki, ${ }^{\mathrm{a}, \mathrm{b}}$ Robert Kucharski, ${ }^{\mathrm{c}}$ Grzegorz Targowski, ${ }^{\mathrm{a}}$ Malcolm A. Watson, ${ }^{\mathrm{d}}$ Henry White, ${ }^{\mathrm{d}}$ Scott Watson, ${ }^{\mathrm{e}}$ and \\ Antony E. Kelly \\ ${ }^{a}$ TopGaN Ltd., ul. Sokolowska 29/37, 01-142 Warsaw, Poland \\ bInstitute of High Pressure Physics PAS, ul. Sokolowska 29/37, 01-142 Warsaw, Poland \\ ${ }^{c}$ Ammono S.A., Czerwonego Krzyża 2/31, 00-377 Warsaw, Poland \\ 'BAE Systems Advanced Technology Center, FPC 267, PO Box 5, Bristol, BS34 7QW, United Kingdom \\ eUniversity of Glasgow, School of Engineering, Glasgow G12 8LT, United Kingdom
}

\begin{abstract}
AIGalnN ridge waveguide laser diodes are fabricated to achieve single-mode operation with optical powers up to $100 \mathrm{~mW}$ at $\sim 420 \mathrm{~nm}$ for visible free-space, underwater, and plastic optical fiber communication. We report high-frequency operation of AlGalnN laser diodes with data transmission up to $2.5 \mathrm{GHz}$ for free-space and underwater communication and up to $1.38 \mathrm{GHz}$ through $10 \mathrm{~m}$ of plastic optical fiber. $\odot 2016$ Society of Photo-Optical Instrumentation Engineers (SPIE) [DOI: 10.1117/1.OE.55.2.026112]
\end{abstract}

Keywords: GaN laser; GaN array; GaN systems; underwater communications; plastic fiber communications.

Paper 151571P received Nov. 9, 2015; accepted for publication Jan. 15, 2016; published online Feb. 10, 2016.

\section{Introduction}

AlGaInN laser diodes (LDs) and light-emitting diodes (LEDs) have gained interest for visible-light communications (VLC), including underwater and optical fiber communications, since the AlGaInN material system allows for devices to be fabricated over a very wide range of visible wavelengths. Recently, it has been shown that microLEDs have $\mathrm{MHz}$ modulation bandwidths. ${ }^{1,2}$ However, the performance of LEDs is limited by moderate bandwidths, low power, and a rapidly divergent beam giving short reach performance hence potential system applications are limited.

In comparison, AlGaInN laser diodes have the potential for much higher modulation frequency, higher powers, and better beam quality giving long reach performance, therefore allowing many new VLC applications to be realized, including, free-space data links using the 422- and 486-nm Fraunhofer lines for low solar background, blue-green underwater data communication, and wavelength multiplexing for plastic fiber communication.

In this paper, $\mathrm{GHz}$ data transmission using directly modulated AlGaInN laser diodes, both underwater and through plastic optical fiber (POF), is reported.

\section{Results}

One of the major limiting factors in nitride laser diode development has been the lack of a suitable low defectivity and uniform GaN substrate. Recently, single crystal growth of large area, very low dislocation density, and uniform GaN substrates are grown using a combination of high temperature and high pressure, enabling a range of AlGaInN laser technology to be developed.,

*Address all correspondence to: Stephen P. Najda, E-mail: s.najda@ topganlasers.com
A typical AlGaInN laser diode epitaxy structure grown by metal organic chemical vapor deposition (MOCVD) consists of (i) $0.8-\mu \mathrm{m} \mathrm{Al} \mathrm{Al}_{0.08} \mathrm{Ga}_{0.92} \mathrm{~N}$ lower cladding layer, (ii) $50-\mathrm{nm} \mathrm{GaN}$ lower waveguide layer, (iii) $50-\mathrm{nm} \mathrm{In}_{0.02} \mathrm{Ga}_{0.98} \mathrm{~N}$ injection layer, (iv) $\operatorname{In}_{x} \mathrm{Ga}_{1-x} \mathrm{~N} / \mathrm{In}_{0.02} \mathrm{Ga}_{0.98} \mathrm{~N}$ quantum wells $\times 3(3.5 / 9 \AA)$ the indium composition $x$ ( $x=0.05$ to 0.2$)$ and well thickness can be varied to change the emission wavelength, (v) $20-n m \mathrm{Al}_{0.2} \mathrm{Ga}_{0.8} \mathrm{~N}$ electron blocking layer, (vi) $80-\mathrm{nm}$ $\mathrm{GaN}$ waveguide, and (vii) $350-\mathrm{nm} \mathrm{Al}_{0.08} \mathrm{Ga}_{0.92} \mathrm{~N}$ upper cladding. All of the data presented in this paper are for AlGaInN laser diodes grown on the c-plane of the Wurtzite crystal.

AlGaInN epitaxy structures are processed into ridge waveguide LDs, with a typical mesa etch depth of $420 \mathrm{~nm}$, cavity length of $700 \mu \mathrm{m}$, and a stripe width varying from 2 to $10 \mu \mathrm{m}$ (depending on the application). After cleavage, the LDs are $\mathrm{HR}$ coated $\left(5 \times \mathrm{ZrO}_{2} / \mathrm{SiO}_{2}\right.$ quarter-wavelength layers) with $95 \%$ reflectivity and $\mathrm{AR}$ coated with $\sim 5 \%$ reflectivity. Single emitters are mounted p-side up in TO5.6mm packages, laser bars are mounted on custom designed packages as described later in this paper.

Optical power-current-voltage (LIV) and beam profile characteristics for a $2-\mu \mathrm{m}$ ridge waveguide LD structure packaged in a TO5.6mm package are shown in Fig. 1(a). The device has an optical power of $\sim 80 \mathrm{~mW}$, threshold current of $\sim 65 \mathrm{~mA}$, a threshold voltage of $\sim 5 \mathrm{~V}$, a lasing wavelength of $410 \mathrm{~nm}$, and a characteristic temperature $T_{0}$ of $\sim 120 \mathrm{~K}$. A single transverse mode optical beam profile is observed in both the slow and fast axis [see Fig. 1(b)]. ${ }^{5}$

High resolution spectral measurements on 4 different AlGaInN LDs with nominally the same structure, except the indium content is different in the $\mathrm{In}_{x} \mathrm{Ga}_{1-x} \mathrm{~N} / \mathrm{In}_{0.02} \mathrm{Ga}_{0.98} \mathrm{~N}$ quantum well $(\mathrm{QW})$ active region with $x=0.05,0.08,0.12$, and 0.16 giving a wavelength emission of $\sim 382, \sim 405$, $\sim 425, \sim 439 \mathrm{~nm}$ at $\sim 10 \mathrm{~mW} \mathrm{cw}, 20^{\circ} \mathrm{C}$ (see Fig. 2).

0091-3286/2016/\$25.00 @ 2016 SPIE 

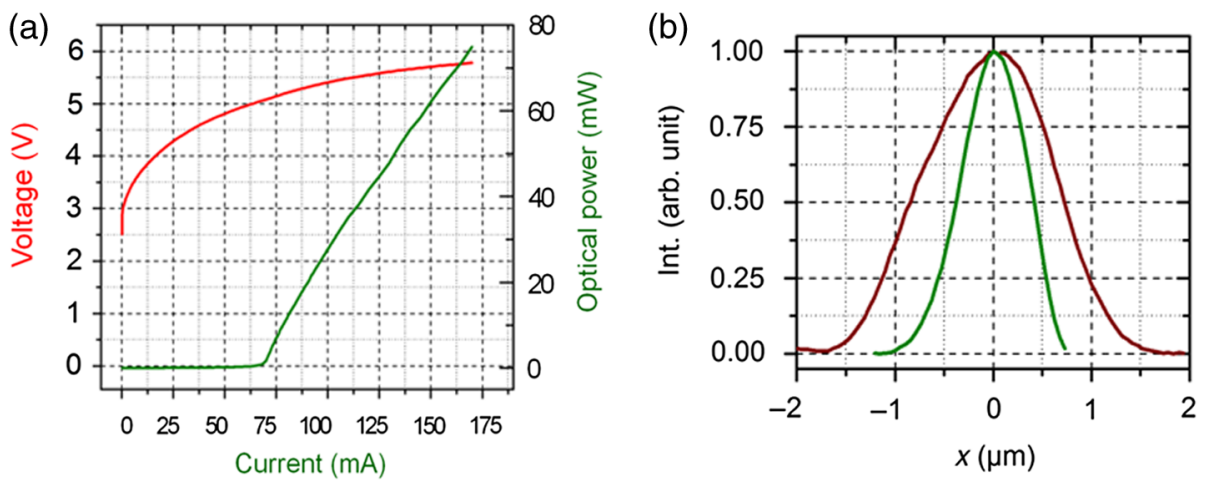

Fig. 1 AIGalnN 410-nm laser diode characteristics: (a) LIV and (b) near-field (slow axis: red line; fast axis: green line).

High-resolution spectral measurements of the AlGaInN LDs reveal the fine mode structure with a characteristic dominant single-longitudinal mode in all of these devices. At first glance, this is a surprising result, since single-longitudinal mode operation is more reminiscent of a DFB type of laser device with etched grating, providing optical feedback for mode selection, rather than a more standard Fabry-Pérot device with no etch grating.

The spectral output of a $\sim 422-\mathrm{nm}$ laser is measured as a function of increasing drive current. For $200 \mathrm{~mA}(14 \mathrm{~mW})$ operation, a dominant single-longitudinal mode at $421.6 \mathrm{~nm}$ with multiple small side modes is observed. As the drive current increases to $250 \mathrm{~mA}(24 \mathrm{~mW})$, the dominant single longitudinal mode remains, and small side modes change position and intensity. At a higher drive current of $300 \mathrm{~mA}(36 \mathrm{~mW})$, the dominant singlelongitudinal mode jumps to a spectrally wide $(\sim 1$ to $2 \mathrm{~nm}$ ) mode comb as it is more typical of a Fabry-Pérot LD device (see Fig. 3).

The single-longitudinal mode operation in a $\mathrm{GaN}$ Fabry-Pérot LD has also been observed in the spectral output of other AlGaInN LDs and was explained by surface roughness inadvertently introduced during growth. ${ }^{6,7}$ Furthermore, it has been proposed that the single mode is stabilized by longitudinal mode competition caused by optical gain saturation. ${ }^{8}$
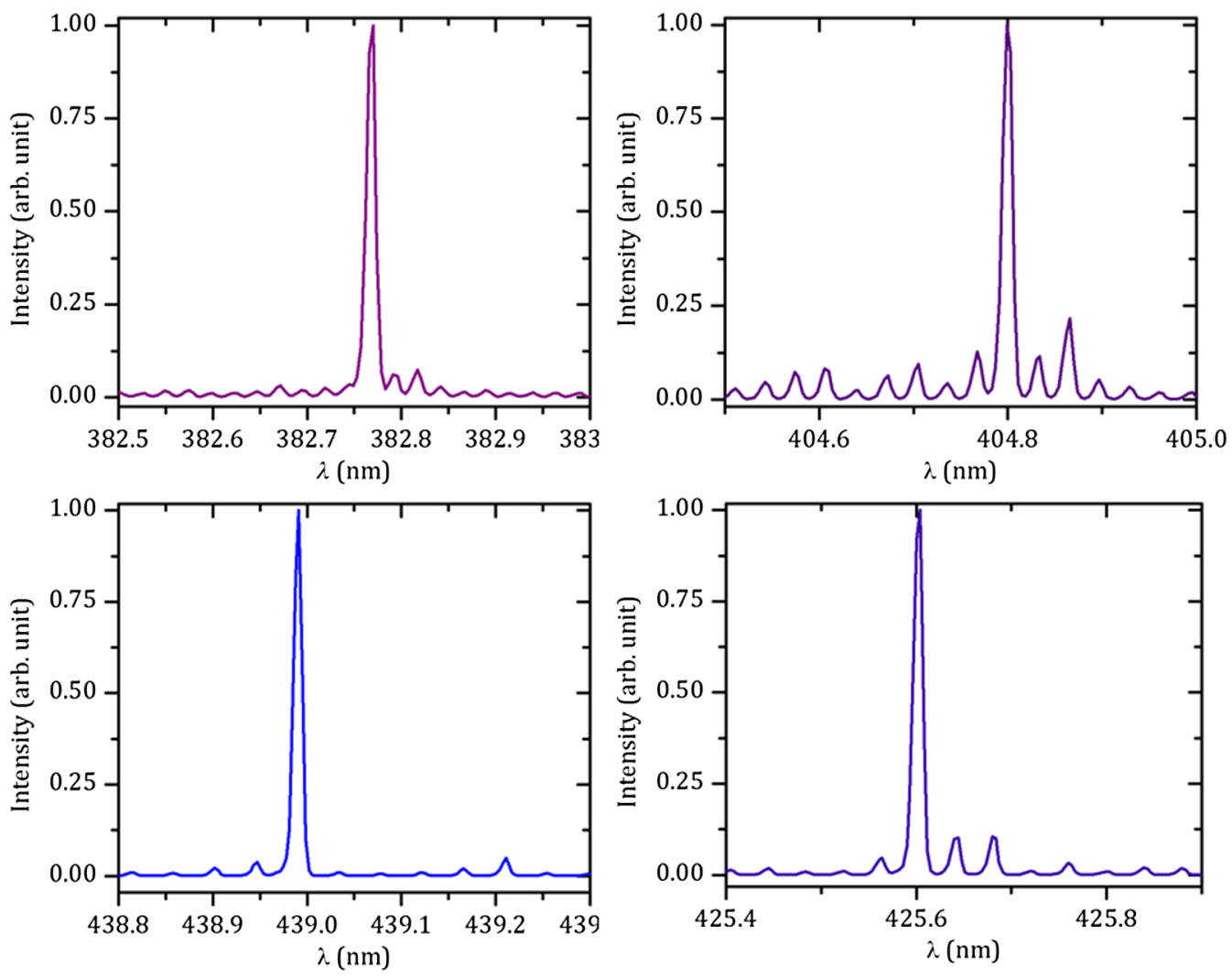

Fig. 2 High-resolution spectra of four different LDs with $Q W$ indium compositions $\ln _{x} \mathrm{Ga}_{1-x} \mathrm{~N}$ / $\mathrm{In}_{0.02} \mathrm{Ga}_{0.98} \mathrm{~N}$ QWs of $x=0.05,0.08,0.12$, and 0.16 giving a wavelength emission of $\sim 382, \sim 405$, $\sim 425, \sim 439 \mathrm{~nm}$ at $\sim 10 \mathrm{~mW} \mathrm{cW}, 20^{\circ} \mathrm{C}$. 

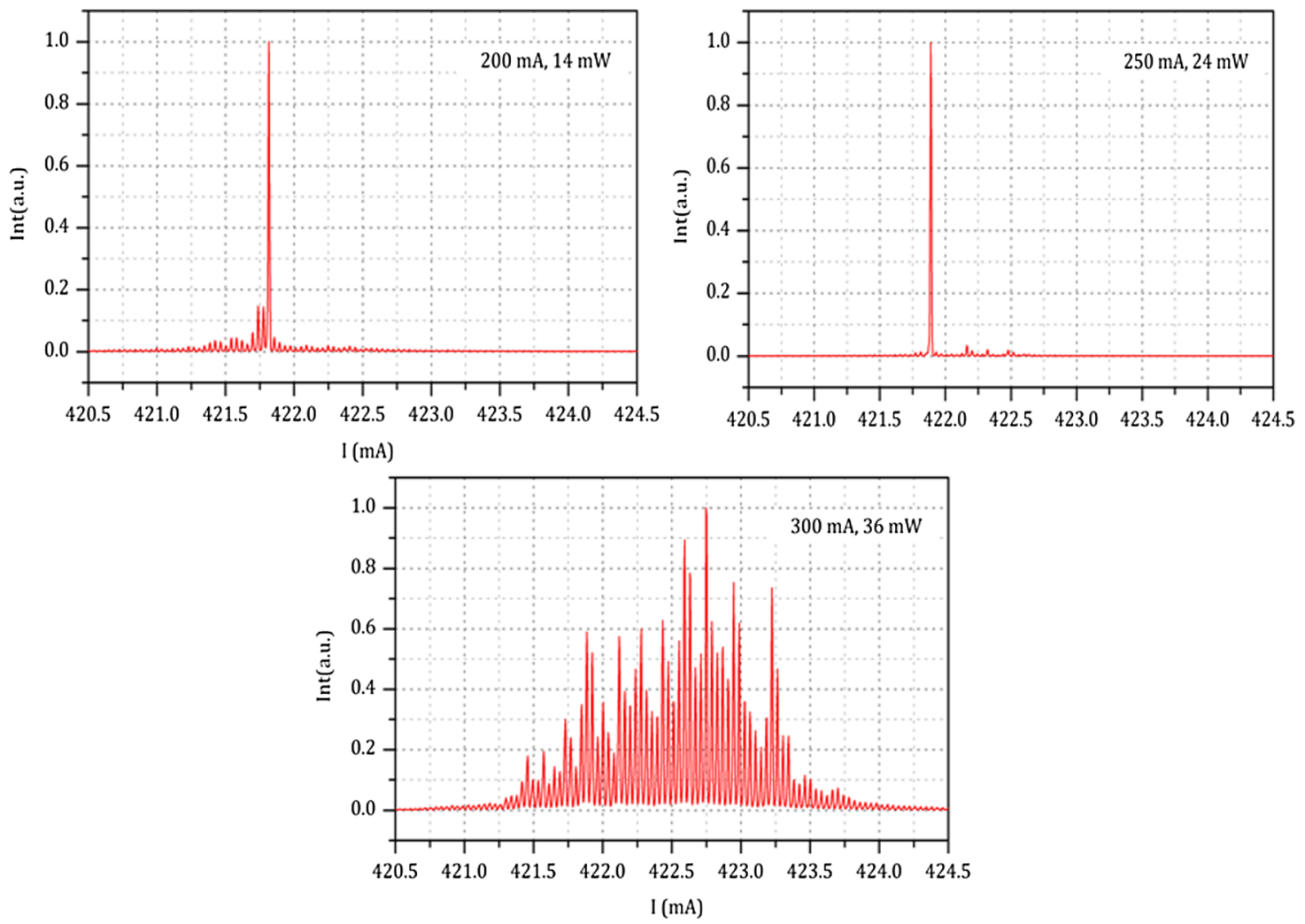

Fig. 3 The evolving spectra of an LD versus increasing drive current $\mathrm{mA} /$ optical power $\mathrm{mW}(\mathrm{cw})$ at $20^{\circ} \mathrm{C}$.

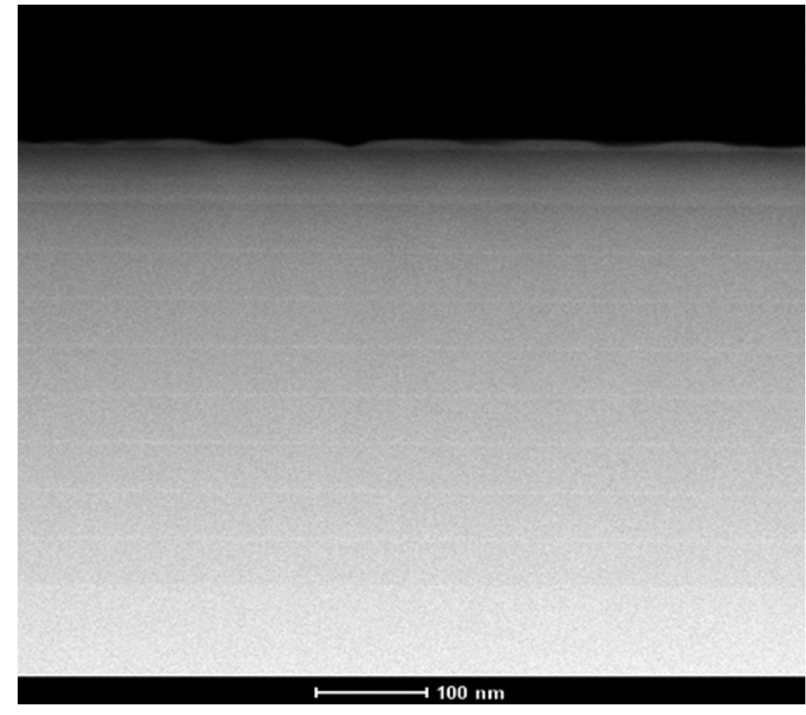

Fig. 4 SEM image of the cross-section of AIGalnN laser epitaxy.

Similarly, we observe a surface topology of the order of $\sim 10 \mathrm{~nm}$ in height and a periodicity of $100 \mathrm{~nm}$ (see Fig. 4). The AlGaInN epitaxy growth is done on very low defectivity $\left(<5 \times 10^{4} \mathrm{~cm}^{-2}\right) \mathrm{GaN}$ substrates with a flatness of $<0.1 \mathrm{~nm}$. ${ }^{9}$ Regardless of the substrate flatness, the surface topology features inadvertently appear in the last epitaxy layer of growth. Thus, we attribute the observed single-mode behavior to the surface topology, creating a periodic refractive index variation, in a similar manner to an etched DFB grating. At higher drive current, the refractive index steps become washed out due to thermal heating and the laser diode operates more like a Fabry-Pérot device and a broad mode-comb is observed in the spectral output of the laser diode.

Free-space data transmission measurements were carried out using GaN blue laser diodes. Eye diagrams, measured using an Agilent 86105B digital sampling oscilloscope, are shown in Fig. 5. High-frequency data transmission (small signal modulation) at $1.1 \mathrm{Gbit} / \mathrm{s}$ was measured for a laser drive current of $115 \mathrm{~mA}$ and $2.5 \mathrm{Gbit} / \mathrm{s}$ for $120 \mathrm{~mA}$, at which the best $Q$-factor margins are achieved. ${ }^{10}$

High-frequency data transmission underwater at similar Gbit/s rates has also been measured using a 422-nm GaN laser diode, demonstrating the suitability of GaN system technology for underwater sensing and communications.

To test the suitability of GaN laser diode technology for underwater communications, a GaN laser optical tracking system was constructed and submerged in a water tank (see Fig. 6). The optical setup is described in more detail elsewhere. ${ }^{11}$ The performance of the GaN laser system was determined as the water conditions were varied by introducing Maalox, which mimics the volume scattering of seawater particles, and it is commonly used in underwater lightscattering experiments. Several GaN laser diodes were tested with their center wavelength in the range of 421 to $425 \mathrm{~nm}$ (varying from device to device). These wavelengths are in the range corresponding to lowest attenuation for optical wavelengths in waters classed as "oceanic clear," whereas with increasing turbidity the lowest attenuation shifts to longer wavelengths.

A GaN laser was fired over a short underwater path length of $\sim 1 \mathrm{~m}$, to conduct data transmission experiments. An initial investigation into underwater data transmission using high-frequency GaN laser diodes is described. The frequency response of the $\mathrm{GaN}$ laser device was measured and 


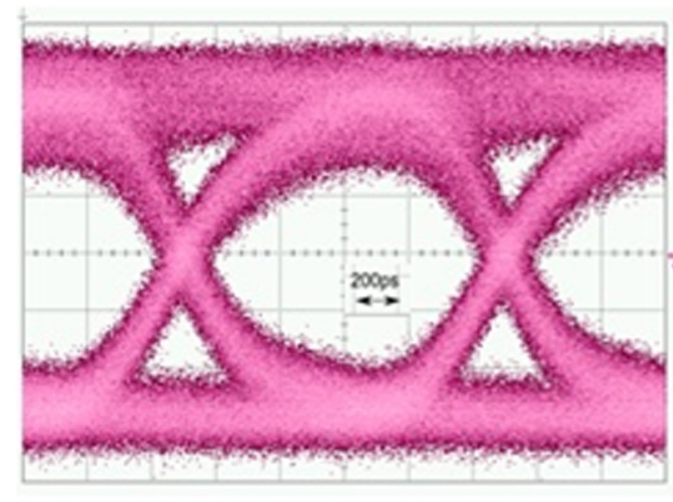

(a)

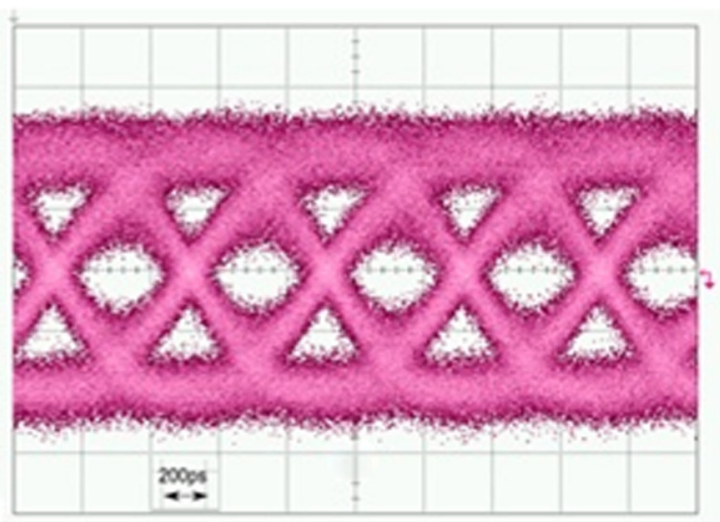

(b)

Fig. 5 Eye diagrams at (a) $1 \mathrm{Gbit} / \mathrm{s}$ and (b) $2.5 \mathrm{Gbit} / \mathrm{s}$ at photoreceiver output.

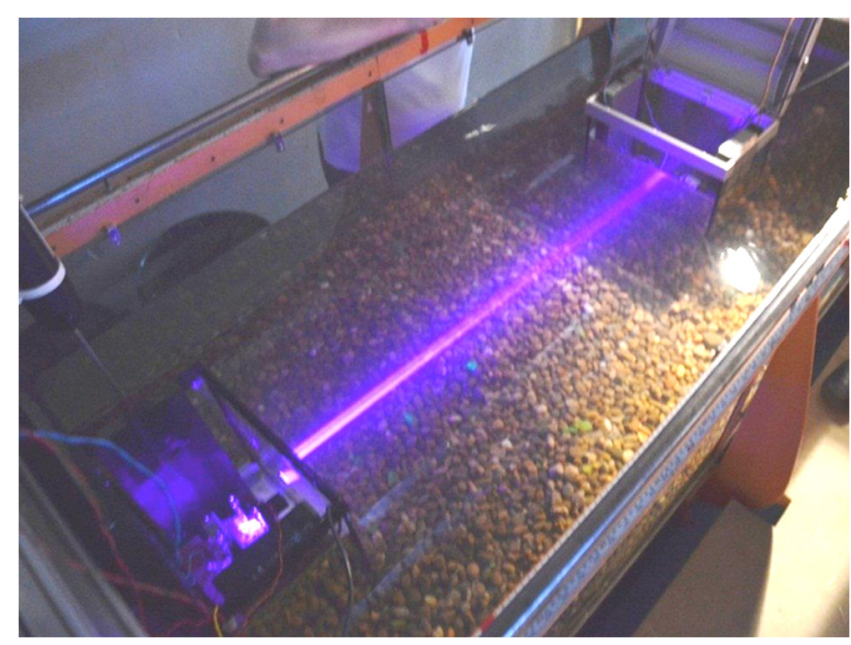

Fig. 6 Collimated laser fired underwater from node to node in harbor type water, over a $\sim 1$-m distance.

eye-diagram data transmission experiments were carried out underwater. In order to measure the bandwidth, the device was driven with a bias current from a constant current source which was combined with an RF signal from a network analyzer to produce a modulated laser output signal. Light from the laser diode was collimated and directed to a high-speed silicon PIN photoreceiver. The underwater path setup was
$1.7 \mathrm{~m}$ in length and the frequency response measurements were carried out as a function of drive current. ${ }^{12}$

For both the air path and water path measurements, the optical $-3 \mathrm{~dB}$ bandwidth values above the laser threshold (at $\sim 100 \mathrm{~mA}$ ) are very similar, showing that the intervening water path has no effect on the bandwidth values. The maximum bandwidth value achieved using this device was $883 \mathrm{MHz}$ at $120 \mathrm{~mA}$.

The relative openness of the "eyes" is a standard measure of the quality of data transmission. A data rate of up to $2.488 \mathrm{Gbit} / \mathrm{s}$ under water can be measured, despite the relatively noisy eye diagram (due to the modulation rate approaching the bandwidth limit of the photoreceiver), there is still sufficient distinction between pulses to resolve the "eyes" of the signal-a visual indication that data transmission is achievable (see Fig. 7). Ultimately, the bandwidth of an underwater optical communication scheme will be limited for longer ranges and higher turbidity levels.

These results show the potential of AlGaInN laser diodes for high-speed data transfer underwater, but also their potential for use in POF. High-speed measurements were conducted through varying lengths of 1-mm diameter stepindex POF (SI-POF). A different laser (from the same batch) emitting at a wavelength of $429 \mathrm{~nm}$ was used to conduct frequency response measurements through the fiber. Fiber lengths of $1,2.5,5$, and $10 \mathrm{~m}$ were tested in order to see the trend of bandwidth against fiber length. This

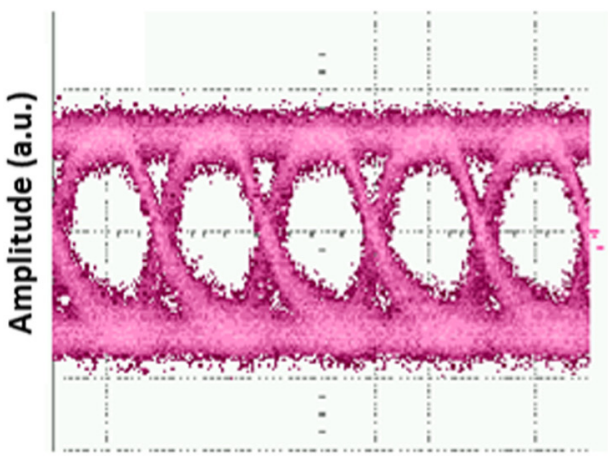

(a)

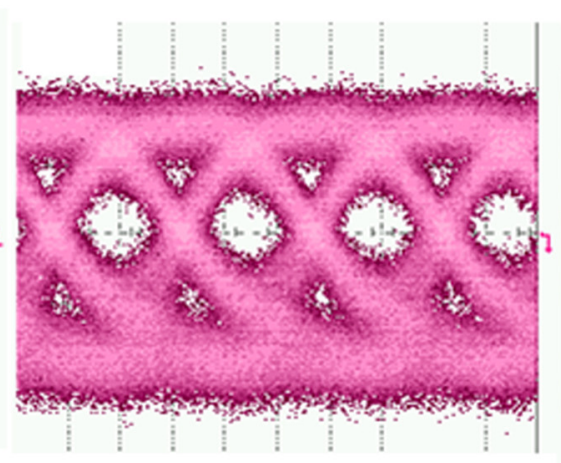

(b)

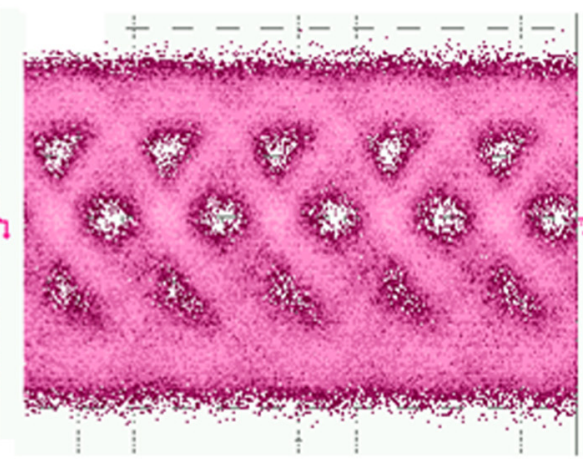

(c)

Fig. 7 Eye diagrams showing data transmission for a signal transmitted through water at (a) $1 \mathrm{Gbit} / \mathrm{s}$ at $125 \mathrm{~mA}$ laser drive current, (b) $2 \mathrm{Gbit} / \mathrm{s}$ at $132 \mathrm{~mA}$, and (c) $2.488 \mathrm{Gbit} / \mathrm{s}$ at $132 \mathrm{~mA}$. 


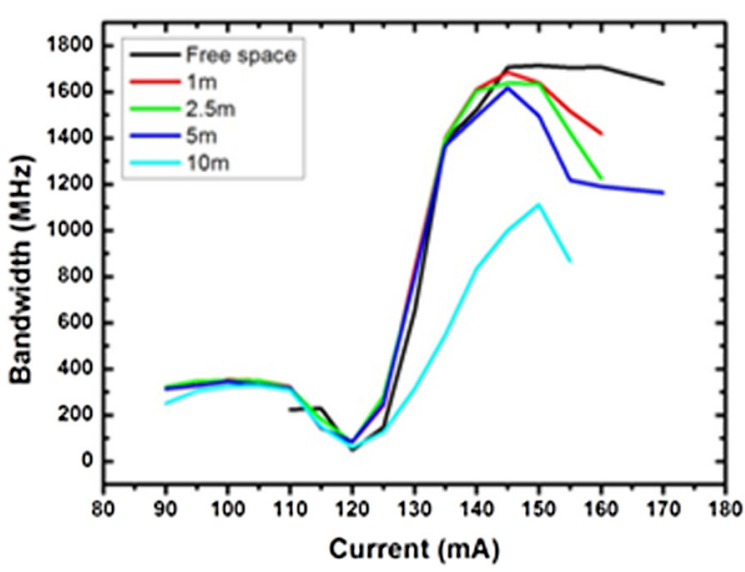

(a)

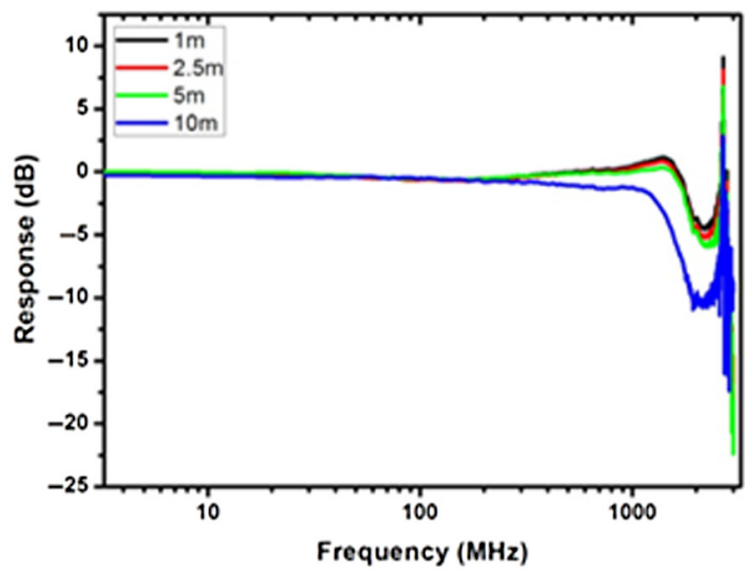

(b)

Fig. 8 (a) Current versus bandwidth for varying lengths of SI-POF and (b) fiber response as a function of length.

device had a $-3-\mathrm{dB}$ bandwidth of $1.71 \mathrm{GHz}$ in free space and could achieve error-free data transmission at $2.5 \mathrm{Gbit} / \mathrm{s}$, in a similar manner as reported above. The maximum bandwidth values achieved for transmission through $1,2.5,5$, and $10 \mathrm{~m}$ of fiber were $1.68,1.63,1.62$, and $1.1 \mathrm{GHz}$, respectively. This can be seen in Fig. 8.

By subtracting the free-space response from measured through different lengths of fiber, the fiber response can be obtained and dispersion analysis carried out. (It should be noted that the laser diode is not optimized for high-frequency operation nor is the laser diode optimized for fiber coupling.) In Fig. 8(b), the bandwidth of a fiber of $10 \mathrm{~m}$ has dropped to $1.38 \mathrm{GHz}$, due to modal dispersion. The dispersion increases as the wavelength decreases and these figures predict values in excess of $10,000 \mathrm{ps} / \mathrm{nm} . \mathrm{km}$. Ultimately, these high dispersion coefficients below $430 \mathrm{~nm}$ will limit the transmission distance when working at this wavelength. ${ }^{13}$

In conclusion, we show Gigabit data transmission using a GaN laser diode in free-space, underwater, and through POF. Different underwater scenarios were tested using a scattering (Maalox) solution that resembles a turbid coastal or harbor region. This work shows the potential for realistic high-bandwidth, laser-based underwater optical communications links using GaN laser diode technology.

\section{Acknowledgments}

This research has been supported by the European Union with Grant No. E!9776 and the National Centre for Research and Development within the project E!9776/ NCBiR/2015.

\section{References}

1. J. McKendry et al., "High-speed visible light communications using individual pixels in a micro-light emitting diode array," IEEE Photonics Technol. Lett. 22(18), 1346-1348 (2010).

2. D. Tsonev et al., "A 3-Gb/s single-LED OFDM based wireless VLC link using a gallium nitride micro-LED," IEEE Photonics Technol. Lett. 26(7), 637-640 (2014).

3. R. Dwilinski et al., "Excellent crystallinity of truly bulk ammonothermal GaN," J. Cryst. Growth 310(17), 3911 (2008)

4. M. Bockowski et al., "Growth of GaN:Mg crystals by high nitrogen pressure solution method in multi-feed-seed configuration," J. Cryst. Growth 350(1), 5 (2012).
5. P. Perlin et al., "Application of a composite plasmonic substrate for the suppression of an electromagnetic mode leakage in InGaN laser diodes," Appl. Phys. Lett. 95, 261108 (2009).

6. T. Meyer et al., "Spectral dynamics of 405nm (Al,In)GaN laser diodes grown on GaN and SiC substrates," Opt. Express 16(10), 6833 (2008).

7. K Holc et al., "Influence of surface roughness on the optical mode profile in GaN-based violet ridge waveguide laser diodes," Proc. SPIE 9002, 90020I (2014).

8. T. Weig et al., "Longitudinal mode competition and mode clustering in (Al,In)GaN laser diodes," Opt. Express 22, 27489 (2014).

9. M. Bockowski et al., "Multi-Feed-Seed (MFS) high pressure crystalisation of 1-2 inch GaN," J. Cryst. Growth 350(1), 5-10 (2012).

10. S. Watson et al., "Visible light communications using a directly modulated 422 nm GaN laser diode," Opt. Lett. 38(9), 3792 (2013).

11. M. A. Watson et al., "Assessment of laser tracking and data transfer for underwater optical communications," Proc. SPIE 9248, 92480T (2014).

12. S. P. Najda et al., "AlGaInN laser diode technology for defence, security and sensing applications," Proc. SPIE 9254, $92540 Z$ (2014).

13. J. Vinogradov et al., "GaN Light emitting diodes for up to $5.5 \mathrm{~Gb} / \mathrm{s}$ Short reach Data transmission over SI-POF," IEEE Photonics Technol. Lett. 26(24), 2473 (2014).

Stephen P. Najda is the VP business development and technical director at TopGaN Ltd. He received his PhD in semiconductor physics from St. Andrews University, followed by research positions at the University of Tokyo and CNRS France. He has almost 20 years of experience in the photonics industry, including commercializing R\&D in an SME environment.

Piotr Perlin is the CTO of TopGaN. He graduated from the University of Warsaw, followed by research positions at the University of New Mexico and Berkeley. He has been involved in many pioneering studies in both basic nitride research and GaN device physics over the last 25 years. He has published over 270 papers in international journals.

Tadek Suski is a professor at Unipress, Institute of High Pressure Physics, Polish Academy of Sciences in Warsaw and has been involved in the physics and applications of nitride semiconductors since 1990 with sabbatical positions at Berkeley and Hokkaido University. He has more than 350 scientific publications with over 5000 citations.

Mike Leszczyński is the vice president of TopGaN and professor at the Institute of High Pressure Physics, Polish Academy of Science in Warsaw. He has authored about 350 papers with 4960 citations on nitride semiconductors and is a regular speaker at international conferences of nitride semiconductors.

Przemek Wisniewski received his Master of Science degree from the University of Warsaw and his PhD from the Institute of Physics, Polish Academy of Sciences (PAS). He was a visiting researcher at the University of Montpellier, France, and at the University of Glasgow, United Kingdom. Currently, he is working as a researcher at the 
Institute of High Pressure Physics PAS and in TopGaN Ltd. He is coauthor of over 80 research papers.

Malcolm A. Watson has over 17 years of experience in optics and laser research. Particular expertise includes fiber and free-space optical communications, hyperspectral and active imaging, photonic crystal fiber power delivery and supercontinuum generation, tunablefrequency laser devices, and electro-optic scene simulation. In 2015, Malcolm joined AVoptics Ltd. from BAE Systems as part of the AVoptics LightWorks team to develop advanced optical and photonics systems.

Henry White joined the Sowerby Research Centre of British Aerospace in 1983, which became the Advanced Technology Centre of BAE Systems in 2000. In 2015, he took up the position of lead technologist sensing within the Military Air \& Information part of BAE Systems. Technical expertise covers fiber optic digital communications, EO sensor technologies, novel imaging systems, high power laser systems, optical wireless communications, and underwater optical systems.

Scott Watson graduated from the University of Glasgow and received his $B E$ degree in electronics with music in 2011. He recently finished his $\mathrm{PhD}$ in the School of Engineering at the University of Glasgow, where his main area of research has been visible light communications using LEDs and laser diodes. He is now continuing to work at the University of Glasgow as a postdoctoral researcher.

Biographies for the other authors are not available. 